\section{THE MACHINABILITY OF INC 718 BY CERAMIC INSERTS}

MATUS VARHANIK, MIROSLAV PISKA

Brno University of Technology, Faculty of Mechanical Engineering, Institute of Manufacturing Technology, Brno

Czech Republic

DOI : 10.17973/MMSJ.2021_6_2020050 matus.varhanik@vutbr.cz; matus.varhanik@mechen.sk

The work deals with a machinability of Inconel ${ }^{\circledR} 718$ construction material (hereafter referred to as "INC 718"). This chromium-nickel alloy has an austenitic structure, which in conjunction with its low thermal conductivity is one of the causes of a worse machinability. The aim of the work was to increase the productivity of the roughing turning process. There are more ways to improve the machinability of the INC 718, starting from the heat treatment of the material and ending with the application of process fluids. This work is based on real requirements of a company and therefore the possibilities of elimination of the worse machinability were limited by economic and technological aspects. For this reason, the main tool for increasing the productivity of the machining process was changing the material of the cutting tool and fine-tuning of the cutting conditions. In another part of the work, an evaluation of the experimentally determined force ratios of the reference and newly designed technology, which is the basis for the stress-strain analysis, have been made. The conclusion of the research highlights the newly designed process in terms of machining times and the volume of material achieved per unit of the cutting edge durability.

KEYWORDS

machinability, hard-to-machine materials, Incone ${ }^{\circledR} 718$, turning with SIALON ceramic, cutting forces

\section{INTRODUCTION}

INC 718 is a superalloy of nickel and chromium blended with controlled alloying elements. The indisputable advantages of this construction material suit applications in machines and other practical activities for endangered expositions. They can be used in such aggressive environments where corrosion resistance is required, in extremely high temperature environments where strength and creep resistance are required, or in cryogenic conditions where toughness is sufficient to ensure stability. INC 718 is successfully used in the temperature range from $-250^{\circ} \mathrm{C}$ to $+750^{\circ} \mathrm{C}$. Typical components made of this material are aircraft engine parts, turbine blades, compressor parts, parts for the oil and gas industry, or medical components. The basic physical constants of the material are given in Table 1 [Thakur 2009].

\begin{tabular}{|c|c|c|}
\hline Physical Property & Value & Units \\
\hline The density & 8.19 & {$\left[\mathrm{~g} \cdot \mathrm{cm}^{-3}\right]$} \\
\hline Melting point of material & $1260-1336$ & {$\left[{ }^{\circ} \mathrm{C}\right]$} \\
\hline Heat capacity & 435 & {$\left[\mathrm{~J} \cdot \mathrm{kg}^{-1} \cdot \mathrm{K}^{-1}\right]$} \\
\hline Thermal conductivity & 11.40 & {$\left[\mathrm{~W} \cdot \mathrm{m}^{-1} \cdot \mathrm{K}^{-1}\right]$} \\
\hline Tensile strength & 1240 & {$[\mathrm{MPa}]$} \\
\hline Young's modulus of elasticity & 200 & {$[\mathrm{GPa}]$} \\
\hline
\end{tabular}

Table 1. Physical properties of Inconel 718. [Thakur 2009], [Inconel 718 technical data 2015]
Indisputable advantages of INC 718 material as mentioned above, bring a high demand on the machining process. Analysis of the original (reference) roughing turning process brought input technological data. The research paper describes the use of ceramic inserts as a progressive cutting material, which can increase the machining productivity and dynamic stability of the part (with the slenderness ratio $L=18.15$ ) several times.

\subsection{Machinability of INC 718}

Machinability of nickel alloys is limited by their low thermal conductivity and the susceptibility of the austenitic structure to cold strengthening. Typical features include a notch wear, abrasive wear on the flank of the tool, the formation of "micro welds" due to the adhesive chip, or plastic deformation of the cutting edge. It is recommended machining the material in a tempered state, as it is possible to achieve a better surface integrity. To reduce the effect of cold hardening, it is advantageous to subject the material to solution annealing and to use cutting tools with positive geometries to avoid the extensive ploughing of the machined surface. Tool face wear can be eliminated with the main cutting angle $\mathrm{K}_{\mathrm{r}}$, ideally in the range of $25^{\circ}$ to $60^{\circ}$ [Tejkl 2012], [AB Sandvik Coromant 2001].

The experiment results show [Li et al. 2002] that PVD-coated carbides KC7310 are more suitable for cutting Inconel 718 than CVD-coated carbides KC935, and ceramic inserts of KY2000 with negative rake angle and KY2100 of round type are the best choice for the high speed turning of Inconel 718.

The effects of cutting conditions and shape of cutting insert on tool wear and tool life when machining Inconel 718 nickel-based super alloy have been experimentally investigated by Altin [Altin et al. 2007]. A series of tool life experiments has been carried out using silicon nitrite based and whisker reinforced ceramic tools which have two different geometries and three different ISO qualities with $10 \%$ water additive cutting fluid. The experiment results show that crater and flank wears were usually dominant wear types in ceramic square type inserts while flank and notch wear are dominant in round type inserts. Minimum flank wear is seen with SNGN tools at low cutting speeds while it is seen with RNGN tools at high cutting speeds.

Encouraging results for coated cemented carbides in turning application have been confirmed by Mrkvica [Mrkvica et al. 2011].

The inlet of liquid supply to the cutting zone influences the behaviour of the machining process itself. The liquid can be supplied to the cutting zone in a standard manner by means of a pump and a supply line. Another method is to supply the liquid to the cutting zone through a core of the tool which should be adapted to this. The liquid may be distributed in the form of a mist, optionally under high pressure. The performance of the cutting fluid can be increased by high efficient cooling. Modern machining approaches indicate the use of gas atmosphere as a substitute for process liquids. In principle, this method has mainly the effect of cooling (compressed $\mathrm{CO}_{2}$ ) and removing (blowing) chips from the cutting zone [Humár 2003], [Fernandez 2014]. Application of high-pressure cooling on the flank face had a positive effect on tool life and overall machining performance of Alloy 718 [Alagan, N.T. et al. 2019].

Tazehkandi compared machining of a chromium-nickel alloy under cutting conditions with a process liquid and without a process liquid. The semi-finished product was Inconel 725 , the cutting tool was sintered with a C-shaped carbide. Lower cutting forces or resistances were measured during dry machining. An exception was the area between 60 to $80 \mathrm{~m} / \mathrm{min}$, where the force values were approximately the 
same. Better surface roughness was achieved in the case of dry machining. Another conclusion of this work is that the use of a coated cutting material is more advantageous than the use of a process fluid due to the decrease in cutting forces and the improvement of surface integrity [Tazehkandi 2014].

Improved machining characteristics can be achieved by applying high-pressure cooling also where the cutting fluid flows directly through the tool and is directed at the cutting edge face to the cutting zone. Due to the high pressure of the liquid, the chip is better formed and broken so that wear of the tool is reduced. This is because the liquid at the rake of the tool forms a lubricating layer upon which the chips leave. When machining INC 718, there is a problem with the thermal conductivity of the material. A way to overcome this drawback is to increase the thermal conductivity of the cutting fluid. A possible solution is also to achieve a turbulent flow of liquid, which leads to an increase of thermal fluxes. The publication Fang (2017) dealt with the adjustment of channel geometry in the tool to create a turbulent flow. In a combination with high pressure (13 $\mathrm{MPa}$ ), area of turbulent flow has been achieved, resulting in an increase in process fluid performance [Fang 2017].

Cryogenic cooling INC 718 brings an increase in the integrity of the surface layer. The service life of the component is considerably prolonged because of pressure stresses that reach a depth of $70 \mu \mathrm{m}$ into the surface. Compared to the dry machining, cryogenic cooling presents the increasement up to $175 \%$. At the same time, the hardness of the surface layer due to cryogenic cooling increased from $500 \mathrm{HV}$ to $800 \mathrm{HV}$. Another advantage of dry or MQL (minimum quantity lubrication) cooling is that the reinforced layer of the austenitic structure has a higher hardness but is also thinner. This is applied in the next machining with advantage. Cryogenic cooling also affects the resulting microstructure. There is a grain refinement compared to classical methods. The plastic deformation of the surface, in the direction of the cutting speed, reaches $1-2 \mu \mathrm{m}$, which is significantly less compared to MQL and dry machining (5-10 $\mu \mathrm{m})$. Liquid nitrogen was used as a cooling medium during the experiment. The nozzle was fed with pressure of $1.5 \mathrm{MPa}$ and the flow rate was $0.6 \mathrm{~kg} / \mathrm{min}$. It was applied to the surface by a pair of nozzles, one aiming at the cut point and the other at the flank of the tool [Pusavec 2011], [Jeyapandiarajan 2019].

The last approach is a combination of several cooling technologies. For example, cryogenic cooling and MQL, or a laser/plasma plus cryogenic cooling. This process can be referred to as a so-called hybrid machining. Using a laser or a plasma can cause the workpiece to heat up just before the tool enters the cut. The tool can be cooled with liquefied nitrogen under the pressure of $1.1 \mathrm{MPa}$. This combination causes a significant reduction in cutting forces, the process becomes more stable, and there is a slower dynamic increase in force/resistance values due to tool wear. This decrease in both shear and cutting forces was approximately $60 \%$ compared to conventional cooling (after 20 seconds of a cut). With the increase in cutting time and the development of wear, the differences promote the hybrid machining method [Piska 2009].

\section{EXPERIMENTAL IMPLEMENTATION - METHODOLOGY}

Originally used sintered carbides were replaced by cutting ceramics, resulting in theoretical assumptions of increasing the volume of material removed per unit time in the semi-rough turning process, as well as greater stability and reliability of the machining process. Parameters of the original technological process are given in Table 2.

Monitored parameter

Data defining the endpoint

\begin{tabular}{|c|c|}
\hline Machine (lathe) & DMG CTX Gama 2000 \\
\hline Tool holder & PDJNL 2525 M15 (Walter AG) \\
\hline Indexable insert (ISO) & $\begin{array}{l}\text { DNMG 150608-NM4 (Walter } \\
\text { AG) }\end{array}$ \\
\hline Insert coating & 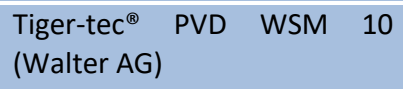 \\
\hline Cutting speed $v_{c}[\mathrm{~m} / \mathrm{min}]$ & 45 \\
\hline Axial depth of cut $a_{p}[\mathrm{~mm}]$ & 2.0 \\
\hline Feed $[\mathrm{mm}]$ & 0.3 \\
\hline $\begin{array}{l}\text { Tool life of cutting edge } \\
T \text { [min] }\end{array}$ & 10 \\
\hline $\begin{array}{l}\text { Material removal rate } \\
\text { MRR }\left[\mathrm{cm}^{3} \cdot \mathrm{min}^{-1}\right]\end{array}$ & 27 \\
\hline $\begin{array}{l}\text { Total material removal } \\
{\left[\mathrm{cm}^{3}\right]}\end{array}$ & 270 \\
\hline
\end{tabular}

Table 2. Reference machining process parameters. [Walter c2000-2016]

The new cutting material was SIALON type ceramic from Kennametal KYS 25 and KYS 30 with defined cutting geometries (Table 3, 4). The KYS 25 grade has a multi-layer $\mathrm{Ti}(\mathrm{C}, \mathrm{N})-\mathrm{Al}_{2} \mathrm{O}_{3}$ coating with a thickness of $20 \mu \mathrm{m}$. The KYS 30 range is uncoated cutting ceramics.

\begin{tabular}{|c|c|}
\hline $\begin{array}{l}\text { Indexable cutting inserts } \\
\text { (ISO) }\end{array}$ & Selected grade \\
\hline CNGA 120412 T01020 & KYS 25, KYS 30 \\
\hline CNGA 120408 T01020 & KYS 25, KYS 30 \\
\hline
\end{tabular}

Table 3. The tested cutting material.

\begin{tabular}{|c|c|c|c|c|}
\hline 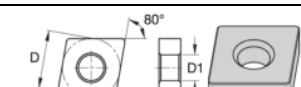 & $\begin{array}{l}\text { D } \\
{[\mathrm{mm}]}\end{array}$ & $\begin{array}{l}\text { L10 } \\
{[\mathrm{mm}]}\end{array}$ & $\begin{array}{l}\mathrm{S} \\
{[\mathrm{mm}]}\end{array}$ & $\begin{array}{l}\mathrm{R} \varepsilon \\
{[\mathrm{mm}]}\end{array}$ \\
\hline $\mathrm{Re}-\mathrm{L10}-\mathrm{S}-$ & 12.7 & 12.896 & 4.76 & 1.2 \\
\hline
\end{tabular}

Table 4. The geometry of the CNGA 120412 T01020 insert. [Novo Kennametal c2017]

The experiment was divided into two fundamental areas. The first was a collection of data and parameters that had been found at the turning process in real conditions in a company. Final value of cutting parameters was achieved by their successive adjusting. Subsequently, the cutting forces generated by these final parameters were measured.

The second part of the experiment was an evaluation and analysis of measured interacting force characteristics with subsequent determination of conclusions using the ANSYS Workbench 2019 R1 simulation program.

One of the outputs of the experiment was a comparison of the effect between dry machining and machining with the maximum supply of cutting fluid provided by the machine tool for tool life of inserts in machining INC 718.

\subsection{Definition of used tools and machines}

Based on the customer's technological requirement (corner machining) the main cutting angle $\mathrm{K}_{\mathrm{r}}=95^{\circ}$ was chosen. Another reason was a minimal generation of a passive force. The nose radii of main cutting edges were $r_{\varepsilon}=1.2$ and $0.8 \mathrm{~mm}$. The first option was to use inserts with a $1.2 \mathrm{~mm}$ radius for a greater stability and the ability to set more productive cutting parameters. In the case that the generated forces would cause the M-T-W (machine-tool-workpiece) system to oscillate, inserts with a radius of curvature of the main cutting edge $r_{\varepsilon}=0.8 \mathrm{~mm}$ 
would be tested. The insert was clamped with the DCNL 2525 M12 KC04 tool holder [Novo Kennametal c2017].

Testing was performed at the DMG CTX Gama 2000 with Siemens Sinumerik $840 \mathrm{D}$ control system. The machine has a main spindle power of $52 \mathrm{~kW}$ and reaches a maximum speed of $2500 \mathrm{rpm}$. The ZEISS Stemi $2000-C$ optical microscope was used to evaluate the shape and structure of the chip and wear of inserts.

Cutting forces were measured using the Kistler dynamometer, type 9257 B. Inserts that showed the highest durability under selected technological conditions on the DMG machine were analysed. The dynamometer is capable to acquire data for three force components in the $\mathrm{X}, \mathrm{Y}, \mathrm{Z}$ axes. The measuring device was fastened with screws to the TOS SUI 50 lathe support. The tool holder was mounted on a fixture that was attached to the dynamometer (Figure 1). The measuring device was connected to the Kistler 5070A multichannel charge amplifier, the data output was captured by the computer using DynoWare.

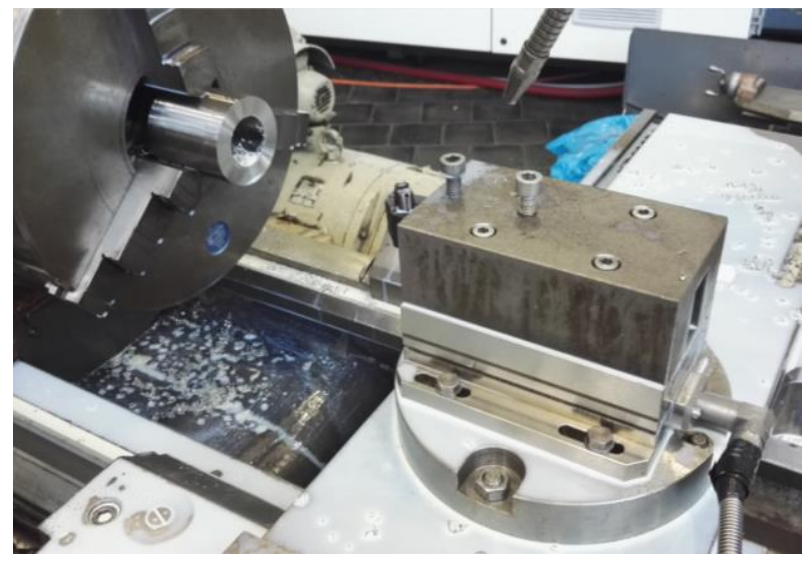

Figure 1. The dynamometer type 9257B with the clamp holder.

\subsection{Risks from workpiece geometry}

The part to be machined was a shaft with the slenderness ratio $\mathrm{L}=18.15$ (the length of the part was $690 \mathrm{~mm}$ and the minimal diameter of the part was $38 \mathrm{~mm}$ ).

A potential risk of the new technology can be seen in the unknown magnitudes of the cutting forces generated during turning that could cause the component to oscillate. This problem occurred when the company originally tried to replace the sintered carbide with a circular cutting ceramic (ISO 513 inserts - R). This shape of the insert is the most advantageous in terms of setting the productive machining parameters, but absolutely unsuitable for components with a large slenderness ratio (Figure 2, Figure 3).

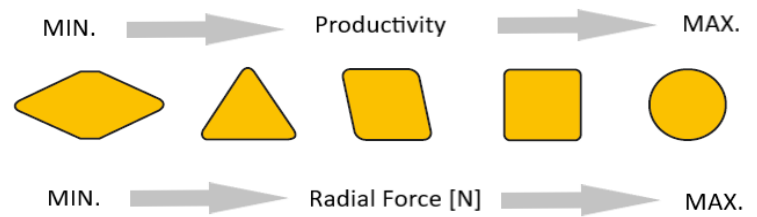

Figure 2. Effect of insert shape on productivity. [Application guide 2010]

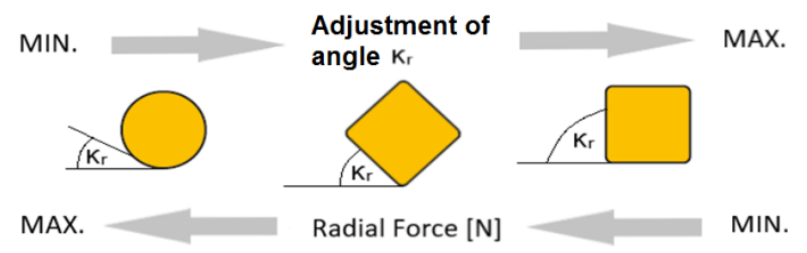

\section{RESULTS}

Turning of the machining conditions based on the above assignment took place at the DMG CTX Gama 2000. Initial values were parameters recommended by the insert manufacturer. These values were further adjusted in order to obtain a satisfactory ratio between the volume of material removed and the tool life. The grade of the insert that showed better results for the application was determined. Results were arranged chronologically and reflected the test procedure itself (Table 5).

\begin{tabular}{|l|l|l|l|l|l|l|}
\hline \multirow{2}{*}{$\begin{array}{l}\text { Monitored } \\
\text { parameter }\end{array}$} & 1 & 2 & 3 & 4 & 5 & 6 \\
\hline Inserts grade & 30 & 30 & 30 & 25 & 25 & 25 \\
\hline $\mathrm{V}_{\mathrm{c}}[\mathrm{m} / \mathrm{min}]$ & 180 & 200 & 200 & 200 & 180 & 180 \\
\hline $\mathrm{a}_{\mathrm{p}}[\mathrm{mm}]$ & 3.0 & 2.0 & 1.0 & 1.0 & 1.0 & 1.0 \\
\hline $\mathrm{f}[\mathrm{mm}]$ & 0.2 & 0.2 & 0.35 & 0.35 & 0.28 & 0.28 \\
\hline Tool life T [min] & 1.5 & 1.5 & 2.4 & 4.7 & 12.7 & 12.2 \\
\hline Process liquid & YES & YES & YES & YES & NO & YES \\
\hline
\end{tabular}

Table 5. Data from the experimental testing on the machine DMG CTX Gama.

The process liquid (a standard emulsion in $7 \%$ weight concentration in water) was fed to the cutting zone by a copper tube as showed in Figure 4 at the highest machine setting - fluid flow $20 \mathrm{l} / \mathrm{min}$ at the pressure $0.2 \mathrm{MPa}$.

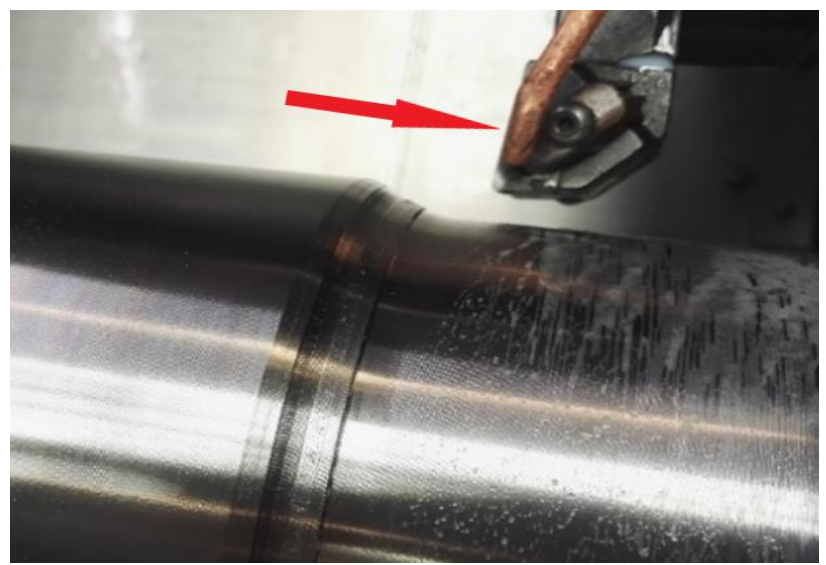

Figure 4. Supply of process liquid to the cutting edge.

The tool life of the cutting edge was unsatisfactory in cases 1 and 2 (Table 5). In both cases, the same factor was responsible for the occurrence of the phenomenon and the subsequent catastrophic failure of the cutting edge. This factor showed the forming of the material in front of the tool, resulting in a burr formation on the unmachined surface (Figure 5).

Figure 3. Effect of the main cutting-edge adjustment on generated passive force. [Application guide 2010] 
This caused mechanical shocks to the minor flank of the cutting insert leading to a fracture of the insert.

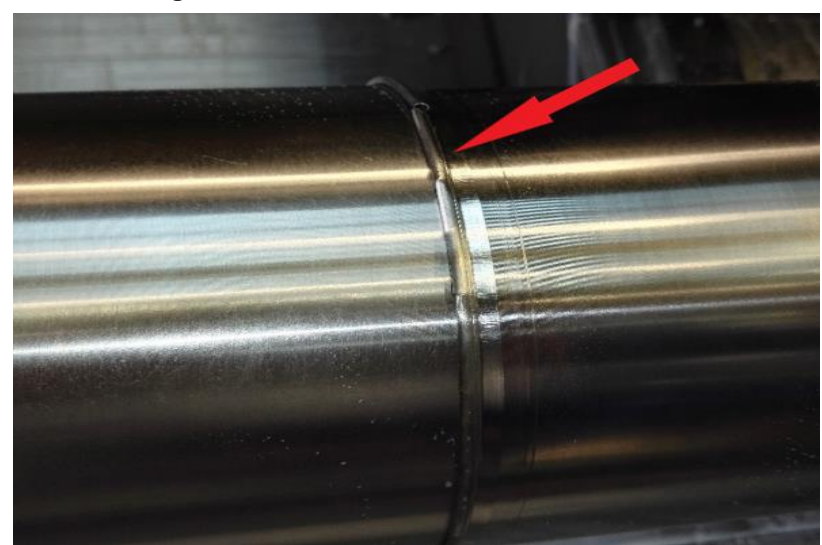

Figure 5. Generation of a "flange" on the non-machined surface.

A possible solution was to use insert geometry with a main cutting angle $\mathrm{K}_{\mathrm{r}}<90^{\circ}$. Nevertheless, it was rejected from the technological point of view. For this reason, it was necessary to reduce the depth of cut of the main cutting $a_{p}$ to $1 \mathrm{~mm}$ with the tip radius of the insert $1.2 \mathrm{~mm}$. In this way, a combination of the advantages of R-shaped and C-shaped inserts were applied. The machining was carried out by the nose radii of inserts with a possibility to make perpendicular surfaces as desired. The main cutting angle $\mathrm{k}_{r}$ was less than $90^{\circ}$ (Figure 6), thus eliminating the formation of burrs.

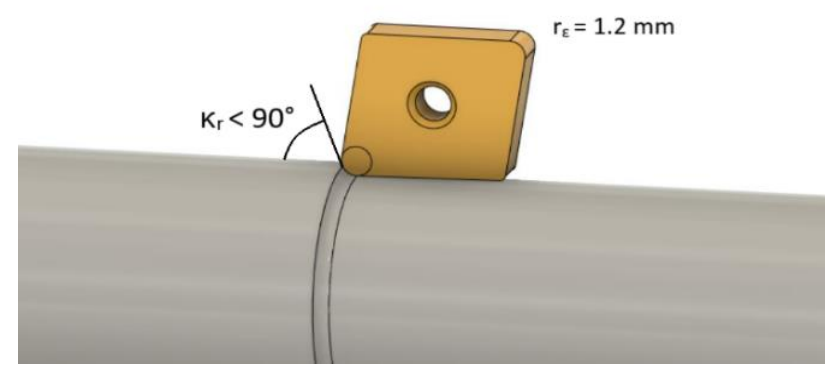

Figure 6. Scheme of the machining regarding the engaged tip.

Further testing continued with the modified parameters (Test Nr. 3). The feed rate was increased in order to eliminate the lower material rate due to the reduction of the width of the main cutting edge. The increase in durability over the original variant was approximately $60 \%$, but the expected durability limit of 6 to 8 minutes was not reached (Table 5). Therefore, a more powerful coated KYS 25 cutting material (Table 5) was used in the following tests $(4,5,6)$. The cutting edge (SIALON ceramic grade, coated) exhibited almost doubled durability under the same machining conditions. Microscopic images of the wear of the forehead and the back of the instrument at the end of Test no. 5 are shown in Figure 7.

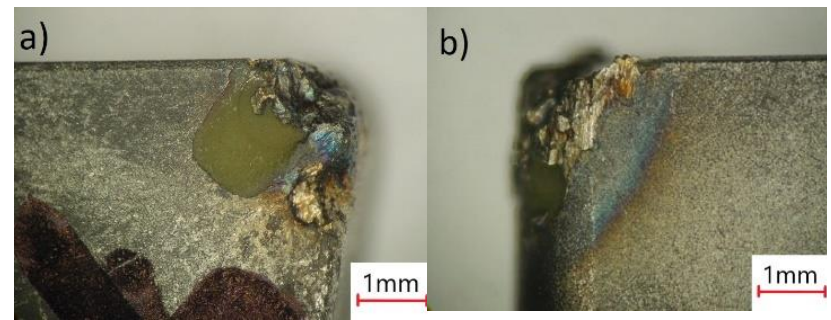

During machining, the resulting chip was removed and changed during tool wear (chip from test number 5). Its shape and structure was recorded using an optical microscope (Figure 8).
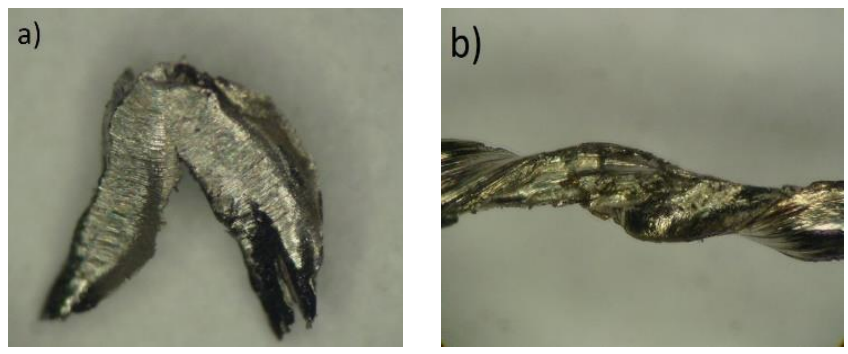

Figure 8. Chips at the beginning (a) and at the end (b) of tool life.

In spite of the low thermal conductivity of INC 718, the generated thermal stress during machining slender shafts could adversely affect the geometrical and mechanical properties of the workpiece. For this reason, test Nr. 6 was performed under the same cutting conditions but using a process fluid (Table 5). Wear of the cutting edge at the end of life is shown in Figure 9.

Compared to the variant of dry machining, there was a significant notch on the flank of the tool and a pothole on the forehead. Nevertheless, due to the need for semi-rough turning of the cylindrical surface, it was possible to machine with sufficient precision. The measured cylindricity at a length of 400 $\mathrm{mm}$ was $0.05 \mathrm{~mm}$.
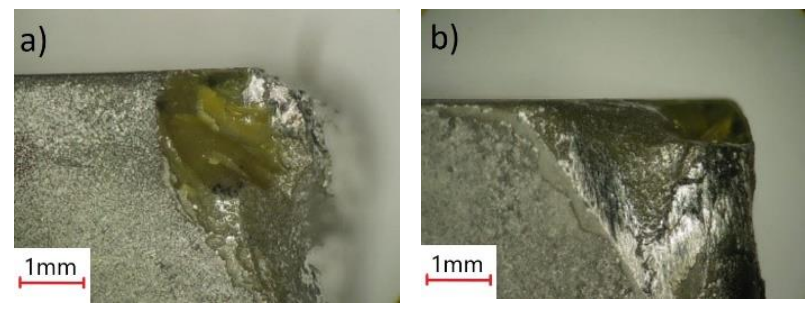

Figure 9. Tool wear of rake (a) and flank (b), condition Nr. 6.

The final machining conditions for the selected application can be found as Nr. 6 in the Table 5. The cutting edge was loaded in time sequences, cutting forces were recorded and at the end of each sequence the chips were removed. The structure and shape of chips in the link with the wear of cutting edge were evaluated by the ZEISS Stemi 2000-C optical microscope (Figure 10-13).
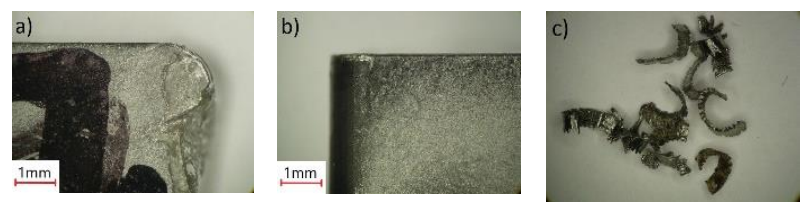

Figure 10. Face (a) and flank (b) wear of inserts and chip shape (c) after 2.2 minutes of cutting.
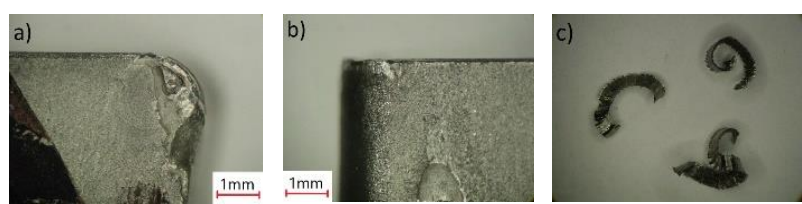

Figure 11. Face (a) and flank (b) wear of inserts and chip shape (c) after 3.5 minutes of cutting.

Figure 7. Tool rake wear (a) and flank wear (b), cutting condition Nr. 5. 

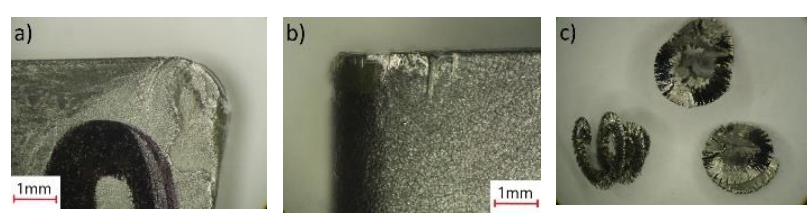

Figure 12. Face (a) and flank (b) wear of inserts and chip shape (c) after 4.4 minutes of cutting.
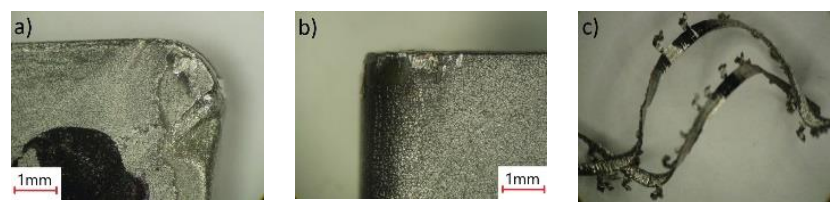

Figure 13. Face (a) and flank (b) wear of inserts and chip shape (c) after 6.5 min of cutting.

\subsection{Analysis of forces when turning}

The following testing focused on the measurement of the cutting forces for both technologies - the origin (WSM 10 sintered carbide) and the up-graded solution (KYS 25 Ceramic inserts). The measured forces (see Table 6) were used as the input data for the stress and deformation calculations.

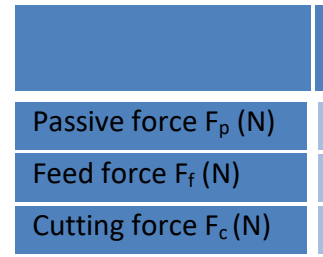

\begin{tabular}{|c|c|}
\hline $\begin{array}{l}\text { Sintered carbide } \\
\text { insert WSM 10 }\end{array}$ & $\begin{array}{l}\text { Ceramic } \\
\text { insert KYS 25 }\end{array}$ \\
\hline 544.20 & 596.30 \\
\hline 730.70 & 450.90 \\
\hline 1790.60 & 821.50 \\
\hline
\end{tabular}

Table 6. Experimental median values of the cutting forces.

The processed and filtered data can be seen in Figures 14 and 15. Facing took place within the diameters of $68 \mathrm{~mm}$ to $40 \mathrm{~mm}$. The spindle speed was kept constant, so the cutting speed for the sintered carbide decreased from $45 \mathrm{~m} / \mathrm{min}$ to $26 \mathrm{~m} / \mathrm{min}$, axial depth of cut was $2 \mathrm{~mm}$ and feed was $0.3 \mathrm{~mm}$. The cutting speed for the cutting ceramic decreased from $180 \mathrm{~m} / \mathrm{min}$ to 105 $\mathrm{m} / \mathrm{min}$, axial depth of cut was $1 \mathrm{~mm}$ and feed was $0.28 \mathrm{~mm}$. These parameters were taken over Table 2 for sintered carbide and Table 5 for cutting ceramic.

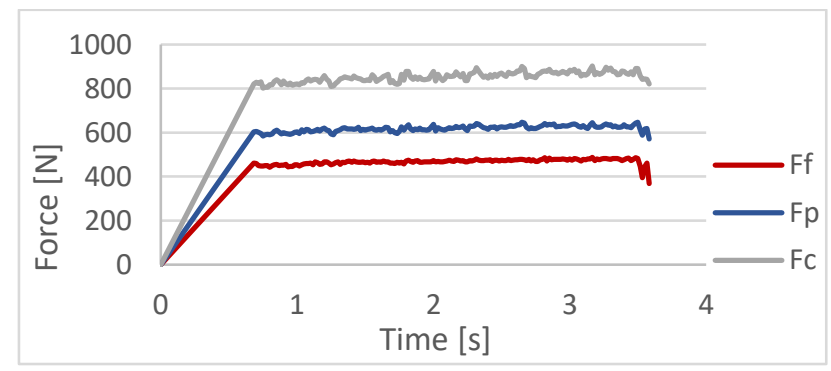

Figure 14. Time development of cutting forces when turning with SIALON ceramic Kennametal KYS 25.

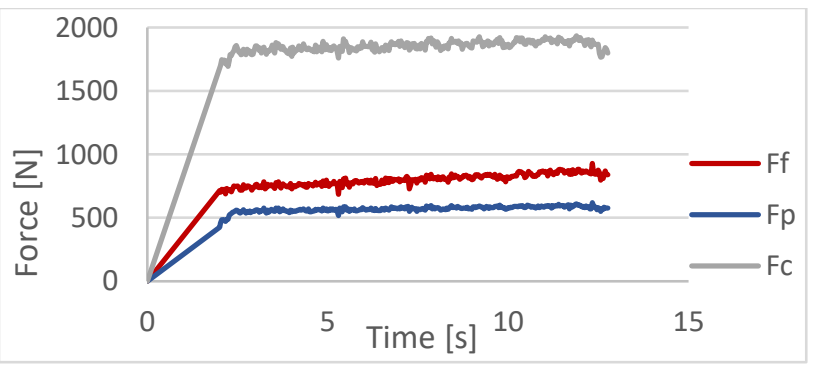

Figure 15. Time development of cutting forces when turning with sintered carbide Walter WSM 10.
The effect of the wear on cutting forces for the ceramic cutting inserts can be seen in Figure 16.

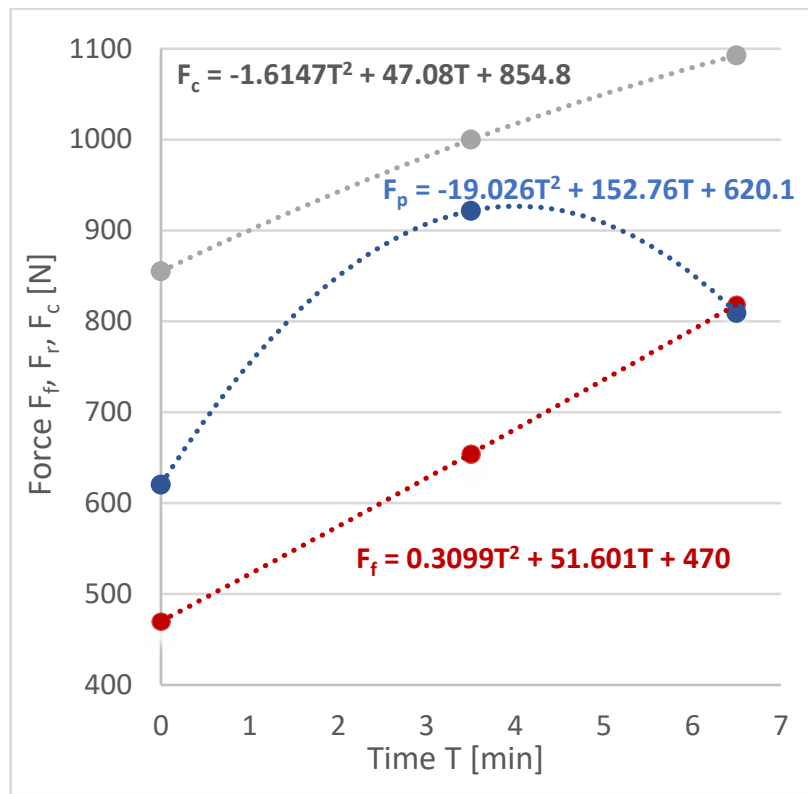

Figure 16. Time sequence of cutting force components reflecting the tool wear (SIALON ceramic Kennametal KYS 25).

In accordance with theoretical assumptions, the wear development of the ceramic inserts resulted into increase of cutting forces. The exception was passive force $F_{p}$. Non-standard behaviour of the passive force could be caused by the change of the tool geometry and formation of a built-up edge. For the sintered carbide the linear increase of all forces was found and reflecting the wear development.

\subsection{Simulation of the generated forces and deformations}

The attention in this part is devoted to the stress-strain analysis of the machined component with ceramic inserts and machining conditions specified in chapters 2.3 and 2.4.

The calculation was performed with the ANSYS Workbench Student License software. The results helped to determine the critical bending points and compared the stress-strain loads arising from the use of sintered carbide and cutting ceramics.

The results of the experimental forces measurement test are presented in Table 6. Because of the face turning, when the spindle speed was constant, the first second of the measurement was taken into account.

The part machined between the tips was released from the physical environment by means of a rotary coupling on the front carrier side and support on the side of the pivoting tip (Table 7). Hydraulic tailstock clamping force reached a value of $5000 \mathrm{~N}$.

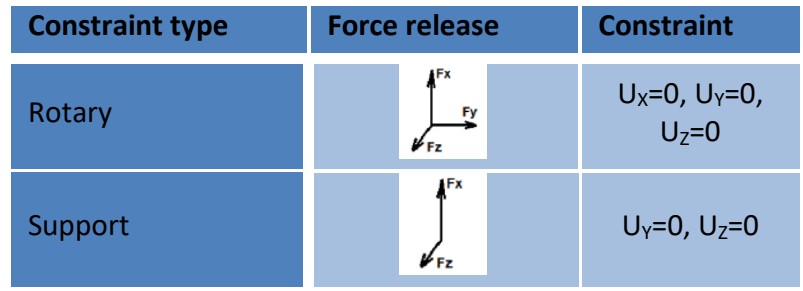

Table 7. Force release of the workpiece under consideration. [Greben 2008]

The calculation included the effect of the cutting speed by calculating the workpiece speed at the minimum machined diameter. The corresponding speed was $380 \mathrm{rpm}$ in the case of 
sintered carbide WSM 10 and $1510 \mathrm{rpm}$ in the case of KYS 25 ceramics respectively.

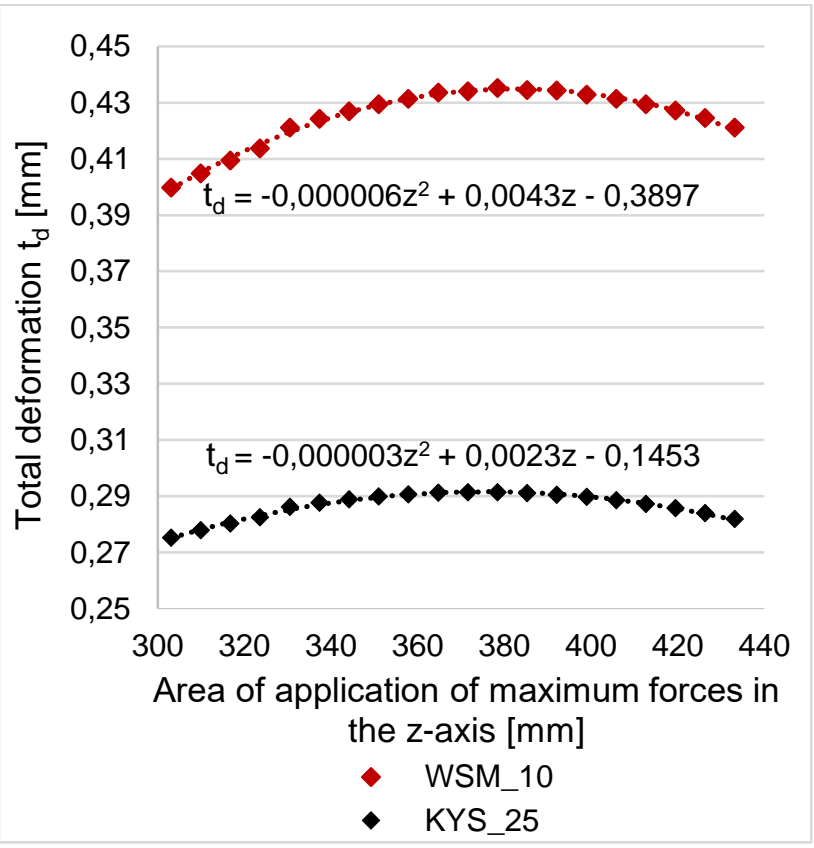

Figure 17. The progress of the part bending due to the machining process.

The calculated deformations can be seen in Figure 17. Figures 18, 19 reflect the component at the moment of maximum deformation. For a better visualization, the results were magnified 50 times. However, the legends describe the real values of the deformations.

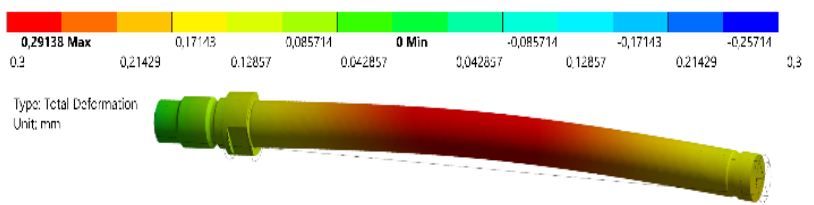

Figure 18. Deformation of the workpiece when turning with KYS 25 cutting ceramic [Ansys Workbench c2018].

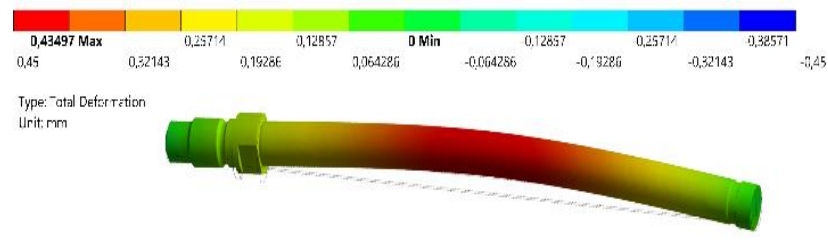

Figure 19. Deformation of the workpiece when turning with sintered carbide WSM 10 [Ansys Workbench c2018].

A very similar deformation occurs in both cases of the simulation in a tangential direction with evident effect of a passive force. The deformations for turning with cutting ceramics were lower in terms of total deformation compared to the results for sintered carbide. Moreover, the process proved to be more stable, without any chattering marks.

\section{SUMMARY AND DISCUSSION}

The total deformation at the most critical bending point was $49 \%$ less when sintered ceramic was used as compared to the sintered carbide. In numerical terms, this total deformation value was lower by 0.143 millimetres. In the case of the optimized variant, the tool life of one cutting edge was reached approximately at the level of the sintered carbide. However, the cutting speed increased four times. The tool life of cutting edge was not defined in consideration of a standard parameter as the VB. The value of the tool life was identified based on the point of the rapid increase of the main spindle load. The spindle load was being monitored in the machine system. On the other hand, the original variant had a $50 \%$ larger depth of cut of the main cutting edge. In the case of KYS 25 cutting ceramics, the machining process exhibited lower bending stress on the workpiece than using the sintered carbide turning reference process. For this reason, it would be advisable to test inserts of the same grade with tool tip radius $r_{\varepsilon}=1.6 \mathrm{~mm}$ in order to apply more productive cutting conditions. Comparing the volume of material removed, the cutting edge durability unit was more productive by $124 \%$ as compared to the sintered carbide (Table 8).

\begin{tabular}{|c|c|c|}
\hline Insert type & $\begin{array}{c}\text { Material } \\
\text { removed per } \\
\text { minute } \\
{\left[\mathrm{cm}^{3} \cdot \mathrm{min}^{-1}\right]}\end{array}$ & $\begin{array}{c}\text { Total material } \\
\text { removal (per } \\
\text { tool life) }\left[\mathrm{cm}^{3}\right]\end{array}$ \\
\hline DNMG 150608-NM4 & 27.0 & 270 \\
\hline CNGA 120412 T01020 & 50.4 & 605 \\
\hline
\end{tabular}

Table 8. Material removed factor reference and new process.

The basic dimensions of the workpiece to calculate the unit machine time of the operation are shown in Figure 20. The calculations did not include the workpiece clamping time and the basic machine and tool settings, as this time was the same for both approaches and did not affect the results.

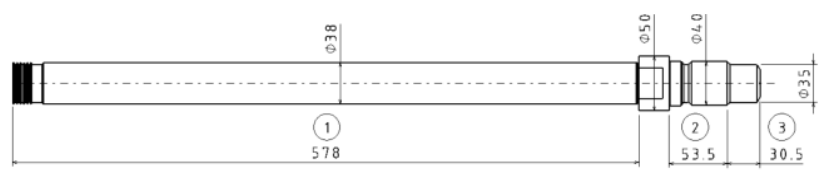

Figure 20. Three sections of the machined part.

As it is a semi-rough turning, the calculation took into account the addition of $1 \mathrm{~mm}$ on the machined diameters. The calculated machine times for both approaches (the reference and the optimized) are reflected in Table 9. The calculations were carried out using the Sandvik Coromant AG TurnCalc software [TurnCalc 2014].

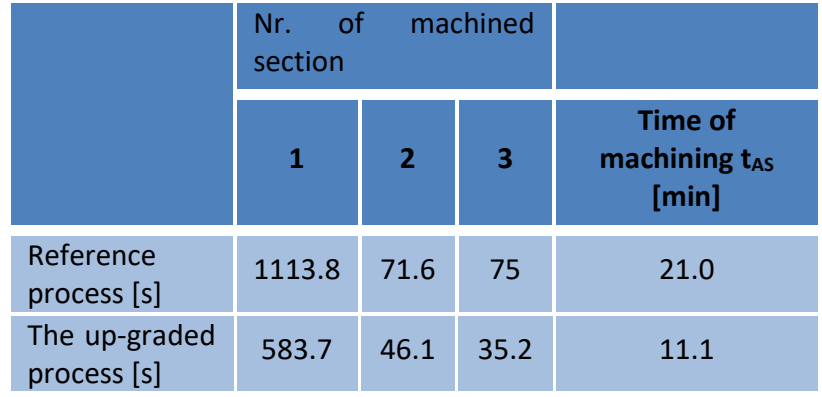

Table 9. The machining times per part.

The tool change time was empirically determined on DMG CTX Gama 2000 machine. It took 1.16 min. The calculation of the 
time for the tool change for each variant is described in Table 10.

\begin{tabular}{|c|c|c|c|c|}
\hline & $\begin{array}{c}\text { Tool } \\
\text { life }\end{array}$ & Time $\mathrm{t}_{\mathrm{AS}}$ & $\begin{array}{c}\text { Nr. of tool } \\
\text { change }\end{array}$ & $\begin{array}{c}\text { Time of } \\
\text { tool } \\
\text { change }\end{array}$ \\
\hline $\begin{array}{c}\text { Reference } \\
\text { process }\end{array}$ & $\begin{array}{c}10 \\
\mathrm{~min}\end{array}$ & $21 \mathrm{~min}$ & 3 & $3.48 \mathrm{~min}$ \\
\hline $\begin{array}{c}\text { The up- } \\
\text { graded } \\
\text { process }\end{array}$ & $\begin{array}{c}12 \\
\mathrm{~min}\end{array}$ & $\begin{array}{c}11.1 \\
\mathrm{~min}\end{array}$ & 1 & $1.16 \mathrm{~min}$ \\
\hline
\end{tabular}

Table 10. Times for the tool exchanges.

$$
\begin{aligned}
& t_{\text {ARef. }}=t_{A S}+t_{A 11}=21,0+3,48=24,48 \mathrm{~min} \\
& t_{A O p t .}=t_{A S}+t_{A 11}=11,10+1,16=12,26 \mathrm{~min}
\end{aligned}
$$

The indisputable advantage of the optimized variant is that the machining process does not need to be interrupted due to the replacement of the cutting edge of the insert. This ensures a greater stability and reliability of the process itself, and also brings benefits in the safety of the CNC machine operator. The calculation of the total unit cycle time $\mathrm{T}_{\mathrm{A}}$ for the above variants is obtained by applying the relations ( 1 and 2 ) for machining times $t_{\mathrm{AS}}$ and time for exchange of tools $t_{\mathrm{A} 11}$.

\section{CONCLUSIONS}

As described above, a change of the cutting material and the correct setting of machining parameters had a fundamental effect on the decreasing machining time, and the increasing stability and the productivity of the machining process of the shaft.

The essential outputs of the research paper were increase in the volume of material removed and the decrease of cutting forces. The ceramic insert was more productive by $124 \%$ as compared to the sintered carbide, and simultaneously with decrease of total deformation at the most critical bending point by $49 \%$ to the sintered carbide.

As a important result of the work the significant improvement of the machining productivity was achieved. As a drawback and the limitation factor can be seen in the impossibility of high pressure cooling (HPC) use. The DMG CTX Gama 2000 lathe was not equipped with the HPC technology.

The use of the HPC technology can have a further significant raise in the process productivity and the tool life because of the convenient effect on the chips formation and lower intensity of tool wear. The reduction of the passive force about $50 \%$ opens a chance for testing of tools with higher nose radii $r_{\varepsilon}$, which can have positive impact on the total volume of material removed.

\section{ACKNOWLEDGMENTS}

This research work was supported by the Brno University of Technology, Faculty of Mechanical Engineering, Specific research 2019, with the grant "Research of perspective production technologies ", FSI-S-19-6014.
[AB Sandvik Coromant 2001] AB SANDVIK COROMANT SANDVIK CZ s.r.o.: Stainless steel turning [in Czech]. 1. ceske vyd. Preklad Miroslav Kudela. Praha: Scientia, 2001, 88 s. Prel. z: Stainless steel turning.

[Alagan, N.T. et al. 2019] Effects of high-pressure cooling in the flank and rake faces of WC tool on the tool wear mechanism and process conditions in turning of alloy 718 , June 2019 . Wear $434-$ 435, DOI: 10.1016/j.wear.2019.05.037.

[ALTIN, A. ET AL. 2007] The effects of cutting speed on tool wear and tool life when machining Inconel 718 with ceramic tools, Materials \& Design, Volume 28, Issue 9, 2007, Pages 2518-2522.

[Ansys Workbench c2018] AnsysWorkbench [program]. Version 19.0. Canonsburg, PA: ANSYS Inc., c2018 [pristup 25 April 2018]

[Application guide 2010] APPLICATION GUIDE: Heat resistant super alloys. 1. Sweden, 2010.08. Available from: https://www.sandvik.coromant.com/sitecollectiondocuments/ downloads/global/technical\%20guides/en-gb/c-2920-034.pdf

[Fang 2017] FANG, Zhenglong a Toshiyuki OBIKAWA. Turning of Inconel 718 using inserts with cooling channels under high pressure jet coolant assistance. Journal of Materials Processing Technology [online]. 2017, 247, 19-28 [cit. 2018-05-18]. DOI: 10.1016/j.jmatprotec.2017.03.032. ISSN 09240136. Available from:http://linkinghub.elsevier.com/retrieve/pii/S0924013617 $\underline{301231}$

[Fernandez 2014] FERNANDEZ, David, Virginia GARCIA NAVAS, Alejandro SANDA a Ion BENGOETXEA. COMPARISON OF MACHINING INCONEL 718 WITH CONVENTIONAL AND SUSTAINABLE COOLANT. MM Science Journal. 2014, 2014(04), 506-510. DOI: 10.17973/MMSJ.2014_12_201415. ISSN 18031269. Available from: http://www.mmscience.eu/december-2014.html\#201415

[Greben 2008] GREBEN, Petr. Calculation of deflection during the machining process [in Czech]. Brno: Brno University of Technology, Faculty of Mechanical Engineering, 2008. 60 s., 1 appendix. Thesis Supervisor: doc. Ing. Miroslav Piska, CSc.

[Humar 2003] HUMAR, A. Technologie I - Machining Technology [in Czech] - 1. Part. Brno University of Technology, Faculty of Mechanical Engineering, Department of Machining Technology. 2003. 138 s. [online]. [cit. 2018-05-16]. Available from: http://ust.fme.vutbr.cz/obrabeni/opory-save/TI_TO-1cast.pdf

[Inconel 718 technical data 2015] INCONEL 718 TECHNICAL DATA. High Temp Metals [online]. California: High Temp Metals, c2015 [cit. 2018-05-16]. Available from: http://www.hightempmetals.com/techdata/hitemplnconel71 8data.php

[Jeyapandiarajan 2019] JEYAPANDIARAJAN, P., M.A. XAVIOR, N.C. SASIDHARAN a A. DUCHOSAL. SURFACE HARDENING AND WEAR CORRELATIONS STUDIES WHEN TURNING INCONEL 718. MM Science Journal. 2019, 2019(04), 3041-3047. DOI: 10.17973/MMSJ.2019_11_2019048. ISSN 18031269. Available from: http://www.mmscience.eu/2019048

[Li, L. et al. 2002] High speed cutting of Inconel 718 with coated carbide and ceramic inserts, October 2002, Journal of Materials Processing Technology 129(1):127-130, DOI: 10.1016/S09240136(02)00590-3.

[Mrkvica, Ivan, et al. 2011] Turning of Inconel 718 by Cemented Carbides." Key Engineering Materials, vol. 496, Trans Tech Publications, Ltd., Dec. 2011, pp. 138-143. Crossref, doi:10.4028/www.scientific.net/kem.46.138. 
[Novo Kennametal c2017] Novo Kennametal [program]. Version2.8.1. Stans: Machining Cloud GmbH, c2017 [10 April 2018]

[Piska 2009] PISKA, Miroslav. Special Machining Technology [in Czech]. Brno: Akademicke nakladatelstvi CERM, 2009. ISBN 97880-214-4025-8.

[Pusavec 2011] PUSAVEC, F., H. HAMDI, J. KOPAC a I.S. JAWAHIR. Surface integrity in cryogenic machining of nickel based alloyInconel 718. Journal of Materials Processing Technology [online]. 2011, 211(4), 773-783 [cit. 2018-05-18]. DOI: $\quad 10.1016 /$ j.jmatprotec.2010.12.013. ISSN 09240136 . Available from: http://linkinghub.elsevier.com/retrieve/pii/S092401361000383 3

[Tazehkandi 2014] HOSSEINI TAZEHKANDI, Ahmadreza, Farid PILEHVARIAN a Behnam DAVOODI. Experimental investigation on removing cutting fluid from turning of Inconel 725 with coated carbide tools. Journal of Cleaner Production. 2014, 80, 271-281. ISSN 09596526. Available from: doi:10.1016/j.jclepro.2014.05.098

[Tejkl 2012] TEJKL, Jakub. Machining of hard to machine materials [in Czech]: Bachelor thesis. Brno: Brno, Brno University of Technology, Faculty of Mechanical Engineering,, 2012. 50s., Thesis Supervisor prof. Ing. Miroslav Piska, CSc.

[Thakur 2009] THAKUR, D.G., B. RAMAMOORTHY a L. VIJAYARAGHAVAN. Study on the machinability characteristics of superalloy Inconel 718 during high speed turning. Materials andDesign [online]. $\quad 2009,30(5), 1718-1725$ [cit.2018-05-21]. DOI: 10.1016/j.matdes.2008.07.011. ISSN 02613069. Available from:http://linkinghub.elsevier.com/retrieve/pii/S0261306908 $\underline{003506}$

[TurnCalc 2014] TurnCalc [program]. Version 1.2.5. Sandviken: Sandvik Coromant AB, 2014 [prístup 25 April 2018]

[Walter c200-2016] On-line katalog Walter. Walter AG [online]. Tubingen: Walter, c2000-2016 [cit. 2018-05-16]. Available from: https://www.walter-tools.com/cs-

$\mathrm{cz} /$ search/pages/default.aspx\#/

\section{CONTACTS:}

Ing. Matus VARHANIK

Brno University of Technology, Faculty of Mechanical

Engineering

Institute of Manufacturing Technology, Department of

Machining Technology

Technicka 2896/2, 61669 Brno, Czech Republic,

+421905670531 Matus.Varhanik@vutbr.cz 